\title{
Pharmacological effects of asiatic acid in glioblastoma cells under hypoxia
}

\author{
Flourina Kumar Thakor ${ }^{1} \cdot$ Ka-Wai Wan $^{1} \cdot$ Philip John Welsby $^{1} \cdot$ Gail Welsby $^{1}$ (i)
}

Received: 5 October 2016 / Accepted: 30 January 2017 / Published online: 15 February 2017

(c) The Author(s) 2017. This article is published with open access at Springerlink.com

\begin{abstract}
Glioblastoma multiforme is the most common and malignant primary brain tumor in adults. Despite current treatment options including surgery followed by radiation and chemotherapy with temozolomide and cisplatin, the median survival rate remains low ( $<16$ months). Combined with increasing drug resistance and the inability of some compounds to cross the blood-brain barrier, novel compounds are being sought for the treatment of this disease. Here, we aimed to examine the pharmacological effect of Asiatic acid (AA) in glioblastoma under hypoxia. To investigate the effects of AA on cell viability, proliferation, apoptosis, and wound healing, SVG p12 fetal glia and U87-MG grade IV glioblastoma cells were cultured under normoxic $\left(21 \% \mathrm{O}_{2}\right)$ and hypoxic $\left(1 \% \mathrm{O}_{2}\right)$ conditions. In normoxia, AA reduced cell viability in U87-MG cells in a time and concentration-dependent manner. A significant decrease in viability, compared to cisplatin, was observed following $2 \mathrm{~h}$ of AA treatment with no significant changes in cell proliferation or cell cycle progression observed. Under hypoxia, a significantly greater number of cells underwent apoptosis in comparison to cisplatin. While cisplatin showed a reduction in wound healing in normoxia, a significantly greater reduction was observed following AA treatment. An overall reduction in wound healing was observed under hypoxia. The results of this study show that AA has cytotoxic effects on glioma cell lines and
\end{abstract}

Electronic supplementary material The online version of this article (doi:10.1007/s11010-017-2965-5) contains supplementary material, which is available to authorized users.

Gail Welsby

GWelsby@uclan.ac.uk

1 School of Pharmacy and Biomedical Sciences, University of Central Lancashire, Preston, Lancashire PR1 2HE, UK has the potential to become an alternative treatment for glioblastoma.

Keywords Glioblastoma $\cdot$ U87-MG · Asiatic acid · Hypoxia

\section{Introduction}

Glioblastoma multiforme (GBM), a grade IV astrocytoma, is the most aggressive and malignant form of glioma. It accounts for $12-15 \%$ of all intracranial tumors and is characterized by molecular heterogeneity and resistance to therapy $[1,2]$. Patients with high-grade glioma have a poor prognosis and median survival is $<5$ years depending on tumor grade, cytogenetic analysis, age, and performance status at the time of diagnosis [2]. Radiotherapy and/or concomitant chemotherapy with adjuvant temozolomide (TMZ) have become the standard of care in GBM [3, 4]. Temozolomide is a prodrug that undergoes metabolic activation following oral administration; thus its in vitro use is restricted [5]. Cisplatin is used to treat recurrent glioma; however, its clinical use is limited due to cellular resistance and dose-dependent toxicity in normal tissue [6-8].

The growth/development and internal organization of all animals depends on the maintenance of oxygen homeostasis and depending on the organ size, function, and tissue location, a wide range of oxygen tension is encountered (0.002-10\%; normal brain 16-21\%) [9, 10]. A drop in oxygen partial pressure activates transcription of hypoxia inducible factor (HIF) leading to changes in cellular metabolism due to transcription of a wide array of genes such as $E G F R$ (epidermal growth factor receptor), VEGFR (vascular endothelial growth factor receptor), and GLUT-1 (glucose transporter-1) [9, 11, 12]. Hypoxia further promotes 
the malignant phenotype of cancer cells, and hypoxic cancer cells often exhibit enhanced resistance to chemotherapy and radiation. Hypoxia is a predominant factor in GBM and plays an important role in tumor growth and progression [13]. Thus, it is important to establish the cytotoxicity of anti-cancer agents under hypoxia.

Asiatic acid (AA) is a pentacyclic triterpenoid extracted from Centella asiatica, native to countries including India and Sri Lanka $[14,15]$. It displays a low side-effect profile and exhibits cytotoxicity against glioblastoma, breast, liver, and colon cancers [16]. In addition, evidence shows that AA can cross the BBB and it has been reported to induce apoptotic cell death in human hepatoma and malignant glioma cells $[17,18]$.

In this study, the pharmacological effects of AA under normoxia $\left(21 \% \mathrm{O}_{2}\right)$ and hypoxia $\left(1 \% \mathrm{O}_{2}\right)$ have been investigated. To calculate drug efficacy, results have been compared to the chemotherapeutic agent, cisplatin.

\section{Materials and method}

\section{Cell culture}

U87-MG (human Grade IV glioblastoma) and SVGp12 (human Fetal glial) cell lines obtained from American Type Culture Collection (ATCC, UK) were maintained in a $37^{\circ} \mathrm{C}$ humidified atmosphere containing $5 \% \mathrm{CO}_{2}$ in Eagles Minimum Essential Media (EMEM), supplemented with $10 \%$ fetal bovine serum, $2 \mathrm{mM} \mathrm{L}$-glutamine, $1 \%$ non-essential amino acids, and $1 \mathrm{mM}$ sodium pyruvate (Lonza, UK). For hypoxic experiments $\left(1 \% \mathrm{O}_{2}, 5 \% \mathrm{CO}_{2}, 94 \% \mathrm{~N}_{2}\right)$, cells were seeded under normoxia $\left(5 \% \mathrm{CO}_{2}, 95 \%\right.$ air $)$ and allowed to adhere for a minimum of $2 \mathrm{~h}$ before transferring to hypoxia using an InvivO $\mathrm{O}_{2} 400$ hypoxia workstation (Baker Ruskinn, UK). Cells were allowed to acclimatize to hypoxia overnight prior to treatment.

\section{Cell viability assay}

Cisplatin and AA (\#P4394 and \#A2612; Sigma Aldrich, UK) concentration-response curves in U87-MG and SVGp12 cell lines were performed under normoxia. Cells were seeded at a density of $10^{3}$ cells/well in 96-well plates and cultured for $24 \mathrm{~h}$ prior to drug treatment $\left(10^{-7}-10^{-4} \mathrm{M}\right)$. Cell viability was measured at 24-, 48-, and 72-h post-treatment using PrestoBlue ${ }^{\circledR}$ (Thermo Fisher Scientific, UK) by measuring fluorescence at an excitation/ emission of 535/612 nm after $1 \mathrm{~h}$ incubation at $37^{\circ} \mathrm{C}$ using a GENios Pro plate reader (Tecan, UK). All treatments were performed in triplicate and a concentration-response analysis was performed (GraphPad Prism 5, GraphPad
Software Inc., USA) to determine $\mathrm{EC}_{50}$ and $\mathrm{EC}_{25}$ concentrations for subsequent assays.

\section{Cell proliferation assay}

Cell proliferation was measured using carboxyfluorescein diacetate succinimidyl ester (CFDA-SE) dye (Cambridge Bioscience, UK). Cells were seeded at a density of $10^{5}$ cells/well in 6-well plates and $24 \mathrm{~h}$ later labeled with CFDA-SE ( $5 \mu \mathrm{M}$ in $1 \mathrm{X}$ PBS) for $30 \mathrm{~min}$. Fresh medium was added and cells were treated with $\mathrm{EC}_{25}$ concentrations of cisplatin $(2 \mu \mathrm{M})$ and $\mathrm{AA}(30 \mu \mathrm{M})$ for 24,48 , and $72 \mathrm{~h}$ under normoxia or hypoxia. Cells were harvested by trypsinization and flow cytometry was performed on a Guava ${ }^{\circledR}$ easyCyte 12HT benchtop flow cytometer (Merck Millipore, UK). A total of 10,000 gated events representing the single cell population were analyzed to determine peak CFDA-SE fluorescence $(488 \mathrm{~nm})$ for each treatment population.

\section{Cell cycle analysis}

U87-MG cells were seeded at a density of $10^{5}$ cells/well in 6-well plates and treated with $2 \mu \mathrm{M}$ cisplatin and $30 \mu \mathrm{M}$ $\mathrm{AA}$, the $\mathrm{EC}_{25}$ determined by the cell viability assay, for $24,48,72$, and $120 \mathrm{~h}$ under normoxia and hypoxia. Cells were harvested by trypsinization, fixed in $70 \%$ ethanol, and stained using 1X PBS containing RNase $(250 \mu \mathrm{g} / \mathrm{ml})$ and propidium iodide $(5 \mu \mathrm{g} / \mathrm{ml})$ for $30 \mathrm{~min}$. Analysis was performed on a Guava ${ }^{\circledR}$ easyCyte $12 \mathrm{HT}$ benchtop flow cytometer (Merck Millipore, UK). A total of 10,000 gated events representing the single cell population were analyzed to determine DNA content by fluorescence intensity $(488 \mathrm{~nm})$ for each treatment population.

\section{Western blot analysis}

U87-MG cells were treated for $48 \mathrm{~h}$ with the $\mathrm{EC}_{50}$ concentration of cisplatin $(10 \mu \mathrm{M})$ and $\mathrm{AA}(50 \mu \mathrm{M})$ as determined by the cell viability assay. Cells were harvested by scraping into $250 \mu \mathrm{l}$ of radio-immunoprecipitation assay buffer (RIPA) with protease and phosphatase inhibitor cocktails (Sigma Aldrich, UK) and solubilization achieved by $1 \mathrm{hr}$ incubation on a rotating wheel at $4{ }^{\circ} \mathrm{C}$. Protein content was normalized by BCA assay, samples $(40 \mu \mathrm{g})$ separated by SDS-PAGE (12\% bis-acrylamide), and transferred to PVDF nylon membranes (GE Healthcare Life Sciences, UK) using a wet transfer kit (Bio-Rad, UK). Membranes were blocked for $1 \mathrm{~h}$ at room temperature with $5 \%$ skimmed milk in Tris-buffered saline-0.1\% Tween 20 (TBS-T), then incubated with cyclin B1 antibody (1:1000 dilution; Cell Signaling Technology, UK) in TBS-T overnight at $4{ }^{\circ} \mathrm{C}$ with gentle shaking. Primary antibody detection was performed following incubation with HRP-conjugated 
secondary antibody (1:2000 dilution; Cell Signaling Technology, UK) at room temperature for $1 \mathrm{~h}$ and visualized by enhanced chemiluminescence (Amersham prime ECL Prime-chemiluminescent agent; Bio-Rad, UK) on a BioRad Molecular Imager ChemiDoc ${ }^{\mathrm{TM}}$ XRS + System with Image Lab ${ }^{\mathrm{TM}}$ Software, UK. Following densitometry, bands were expressed as fold change compared to non-treated normoxic control.

\section{Apoptosis assay}

Cells were seeded at a density of $10^{5}$ cells/well in 6-well plates and treated with $10 \mu \mathrm{M}$ cisplatin and $50 \mu \mathrm{M}$ AA. $\mathrm{EC}_{50}$ was determined by the cell viability assay, under normoxia and hypoxia. Following 24,48 , and $72 \mathrm{~h}$ of treatment, cells were harvested by trypsinization and labeled using the Dead Cell Apoptosis Kit with Annexin-V/Alexa Fluor ${ }^{\circledR} 488$ and Propidium Iodide (Invitrogen/Life Technologies ${ }^{\mathrm{TM}}, \mathrm{UK}$ ) as per the manufacturer's instructions. Analysis was performed by flow cytometry on a FACSAria (BD Bioscience, UK) and Guava ${ }^{\circledR}$ easyCyte 12HT benchtop flow cytometer (Merck Millipore, UK). A total of 10,000 gated events were analyzed and the relative fluorescence $(488 \mathrm{~nm})$ of propidium iodide plotted against Annexin-V/Alexa Fluor $^{\circledR}$ to identify healthy and apoptotic cell populations.

\section{Wound healing/migration assay}

An in vitro scratch assay was performed using U87-MG cells under normoxia and hypoxia. Cells were seeded at $4.5 \times 10^{4}$ cells/well in a 24 -well plate, incubated overnight, and the resulting cell monolayer was scraped in a single line using a sterile toothpick to create a scratch and the media was replaced to remove dislodged cells. Cells were treated with $2 \mu \mathrm{M}$ cisplatin and $30 \mu \mathrm{M} \mathrm{AA}$, the $\mathrm{EC}_{25}$ concentration determined by the cell viability assay. The scratch was imaged immediately, and after $18 \mathrm{~h}$ of incubation, using a modified Zeiss Cell Observer imaging system using a Zeiss Plan-Apo $20 \times 0.8$ NA air objective (Zeiss, UK). Scratch diameter was measured using an average of six points on a minimum of three separate images per treatment using the Zeiss Zen desk software. Results were expressed as percentage closure vs non-treated control.

\section{Statistical analysis}

Statistical analysis was performed using one-way and twoway ANOVA with Bonferroni's post hoc test as described in GraphPad Prism software version 5 (GraphPad Software, GraphPad Software Inc., USA). Significant differences were accepted for $p<0.05$ and have been represented as $* p<0.05, * * p<0.01$, and $* * * p<0.001$. Results were expressed as mean \pm SEM of three individual experiments.

\section{Results}

Dose and time responses for the viability effect of asiatic acid in vitro

The potential of cisplatin and AA to affect U87-MG human glioblastoma cell viability was investigated in vitro and compared to the non-cancerous SVGp12 cell line. A concentration- and time-dependent decrease in cell viability was observed for both cisplatin and AA (Fig. 1). While no overall significant difference was found between each of the treatments $(p>0.05)$, significant differences were observed between $\mathrm{EC}_{50}$ values (Table 1). Following $24 \mathrm{~h}$ of treatment in the U87-MG cell line, the $\mathrm{EC}_{50}$ value for AA was significantly lower than that of cisplatin $(44 \pm 20$ vs. $97 \pm 11 \mu \mathrm{M}$ respectively; $p<0.01)$. However, following 48 and $72 \mathrm{~h}$ of treatment, the $\mathrm{EC}_{50}$ value for cisplatin was significantly lower than that of AA in U87-MG cells $(7.4 \pm 0.4$ vs. $47.4 \pm 3.0 \mu \mathrm{M} ; p<0.05$ and $4.7 \pm 1.0$ vs. $59 \pm 17.0 \mu \mathrm{M}$; $p<0.01$ respectively).

As cell viability can be influenced by multiple factors, it was decided to examine the effects of AA on cell proliferation and apoptosis following $48 \mathrm{~h}$ of treatment using either the $\mathrm{EC}_{50}$ or $\mathrm{EC}_{25}$ as determined by the cell viability assays. Additionally, as the efficacy of treatment can be affected by oxygen levels in the tumor microenvironment, subsequent assays were performed under both normoxia $\left(21 \% \mathrm{O}_{2}\right)$ and hypoxia $\left(1 \% \mathrm{O}_{2}\right)$.

\section{Effect of asiatic acid on U87-MG cell proliferation}

To investigate the effect of AA on U87-MG cell growth, a proliferation assay was performed. Following staining with CFDA-SE, under normoxia, flow cytometric analysis showed a decrease in CFDA fluorescence in untreated cells over $72 \mathrm{~h}$ (Fig. 2a). Cells were treated with cisplatin and $\mathrm{AA}$ under normoxia and hypoxia using the $\mathrm{EC}_{25}$ concentration determined by the cell viability assay. A significant decrease in proliferation was noted in cisplatin-treated U87-MG cells under hypoxia at $48 \mathrm{~h}$ when compared to the non-treated normoxic $(31.5 \pm 7.0$ vs. $14.7 \pm 0.4 \%)$ and hypoxic $(31.5 \pm 7.0$ vs. $13.4 \pm 0.3 \%)$ controls (Fig. $2 \mathrm{~b}, \mathrm{~d}$, $\mathrm{p}<0.05$ ). AA treatment showed no significant decrease in proliferation under normoxia or hypoxia vs either control or cisplatin treatment (Fig. 2c, d). This result indicated that the effect of AA on cell viability was not due to a significant decrease in cell proliferation. Similarly, AA did not reduce SVGp12 cell proliferation (see Online Resource 2). 
Fig. 1 Concentration- and viability following cisplatin and AA treatment at 24,48 , and $72 \mathrm{~h}$ of (a and b) the SVGp12 cell lines. Data represent mean \pm SEM of three independent experiments. Statistical significance determined by ANOVA with Bonferroni's post hoc test $(\mathrm{p}<0.05)$ time-dependent changes in cell and (c and d) the U87-MG
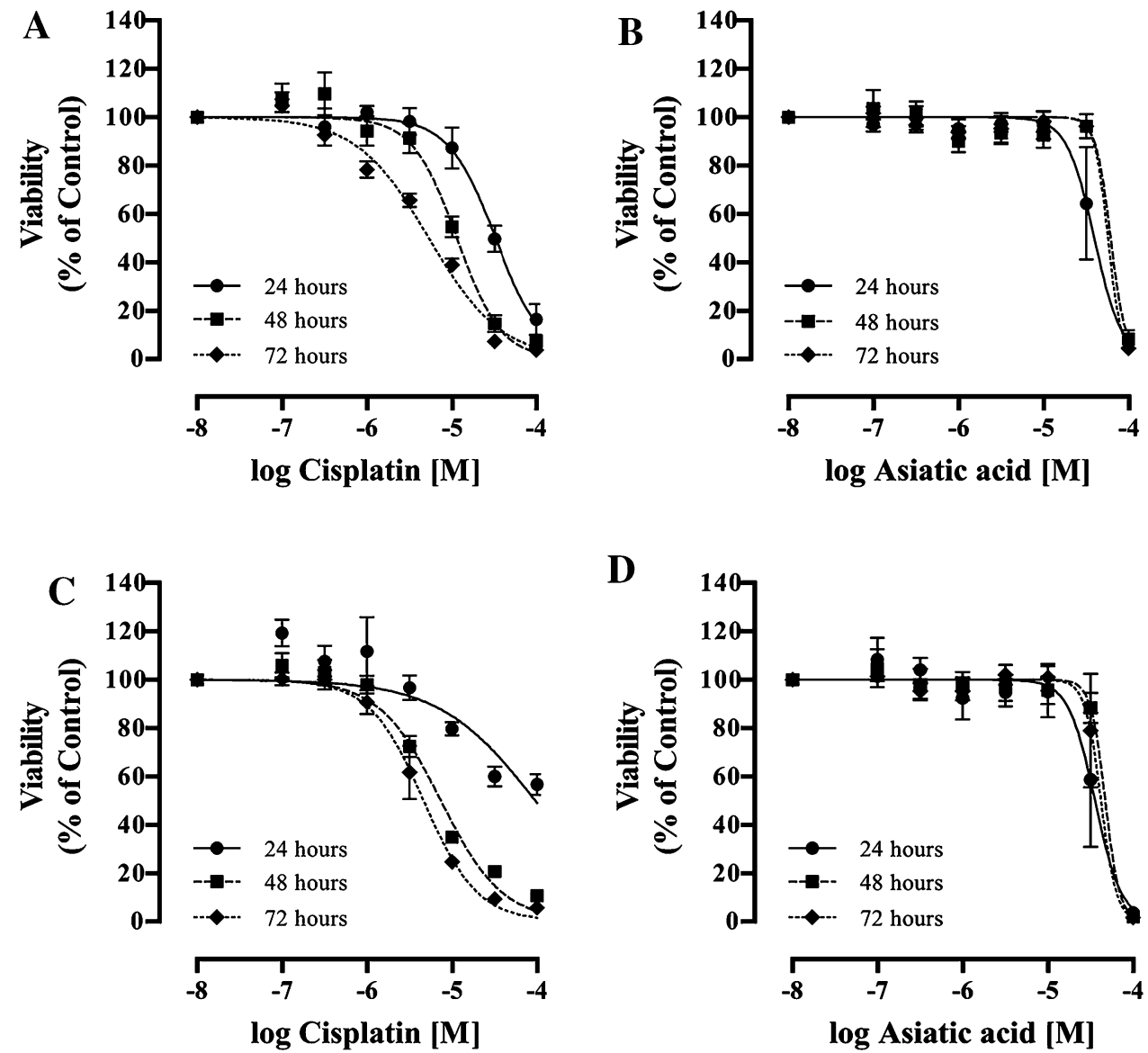

Table 1 Cell viability $\mathrm{EC}_{50}$ values for cisplatin and $\mathrm{AA}$ under normoxia following 24 , 48 , and $72 \mathrm{~h}$ of treatment

\begin{tabular}{|c|c|c|c|c|c|c|}
\hline \multirow[t]{2}{*}{ Normoxia } & \multicolumn{3}{|l|}{$\begin{array}{l}\text { Cisplatin } \\
(\mu \mathrm{M})\end{array}$} & \multicolumn{3}{|l|}{$\begin{array}{l}\text { Asiatic acid } \\
(\mu \mathrm{M})\end{array}$} \\
\hline & $24 \mathrm{~h}$ & $48 \mathrm{~h}$ & $72 \mathrm{~h}$ & $24 \mathrm{~h}$ & $48 \mathrm{~h}$ & $72 \mathrm{~h}$ \\
\hline SVG p12 & $33.8 \pm 7.9$ & $11.2 \pm 1.4$ & $5.4 \pm 0.5$ & $50.3 \pm 18.0$ & $66.6 \pm 7.6$ & $56.6 \pm 3.6$ \\
\hline U87-MG & $97.0 \pm 11.7$ & $7.4 \pm 0.4$ & $4.7 \pm 1.0$ & $44.3 \pm 20.2$ & $47.4 \pm 3.1$ & $59.0 \pm 17.3$ \\
\hline
\end{tabular}

Data represent mean \pm SEM of three independent experiments. Statistical significance determined by ANOVA with Bonferroni's post hoc test $(p<0.05)$

\section{Cell cycle arrest in U87 cells following cisplatin and asiatic acid treatment}

To further establish the effects of cisplatin and AA on cell growth, cell cycle arrest was measured by flow cytometry. Normoxic U87-MG cells treated with the $\mathrm{EC}_{25}$ of cisplatin showed a significant decrease in the proportion of G0/ G1 phase cells compared to non-treated controls (Fig. 3a, $\mathrm{b}$, and $\mathrm{d} ; 30.0 \pm 8.4 \%$ vs. $53.0 \pm 9.6 \% ; p<0.05)$ with a concomitant increase in the proportion of cells in $\mathrm{G} 2 / \mathrm{M}$ phase compared to non-treated controls (Fig. 3a, b, and d; $58.9 \pm 5.7 \%$ vs. $31.8 \pm 8.7 \%$; $p<0.01$ ). AA had no significant effect on U87-MG cell cycle distribution under either normoxia or hypoxia compared to control (Fig. 3c, d).
Neither AA, nor cisplatin treatment at $\mathrm{EC}_{25}$ induced apoptosis (see Online Resource 1).

Western blot analysis of cyclin B1 expression showed an increase in cyclin B1 levels in U87-MG cells following 48-hour cisplatin treatment under normoxia (Fig. 4b), correlating with the cell cycle arrest in $\mathrm{G} 2 / \mathrm{M}$ in these cells. While the cyclin B1 levels following AA treatment were not significantly different from control under normoxia, they were significantly lower than following cisplatin treatment (Fig. 4b $0.24 \pm 0.07$-fold vs. $1.55 \pm 0.22$-fold respectively; $p<0.001)$. Under hypoxia, both non-treated $(0.13 \pm 0.05$ fold; $\quad p<0.05)$ and cisplatin-treated $(0.49 \pm 0.23$-fold; $p<0.01)$ cyclin $\mathrm{B} 1$ levels were significantly lower than their normoxic equivalents (Fig. 4b). 

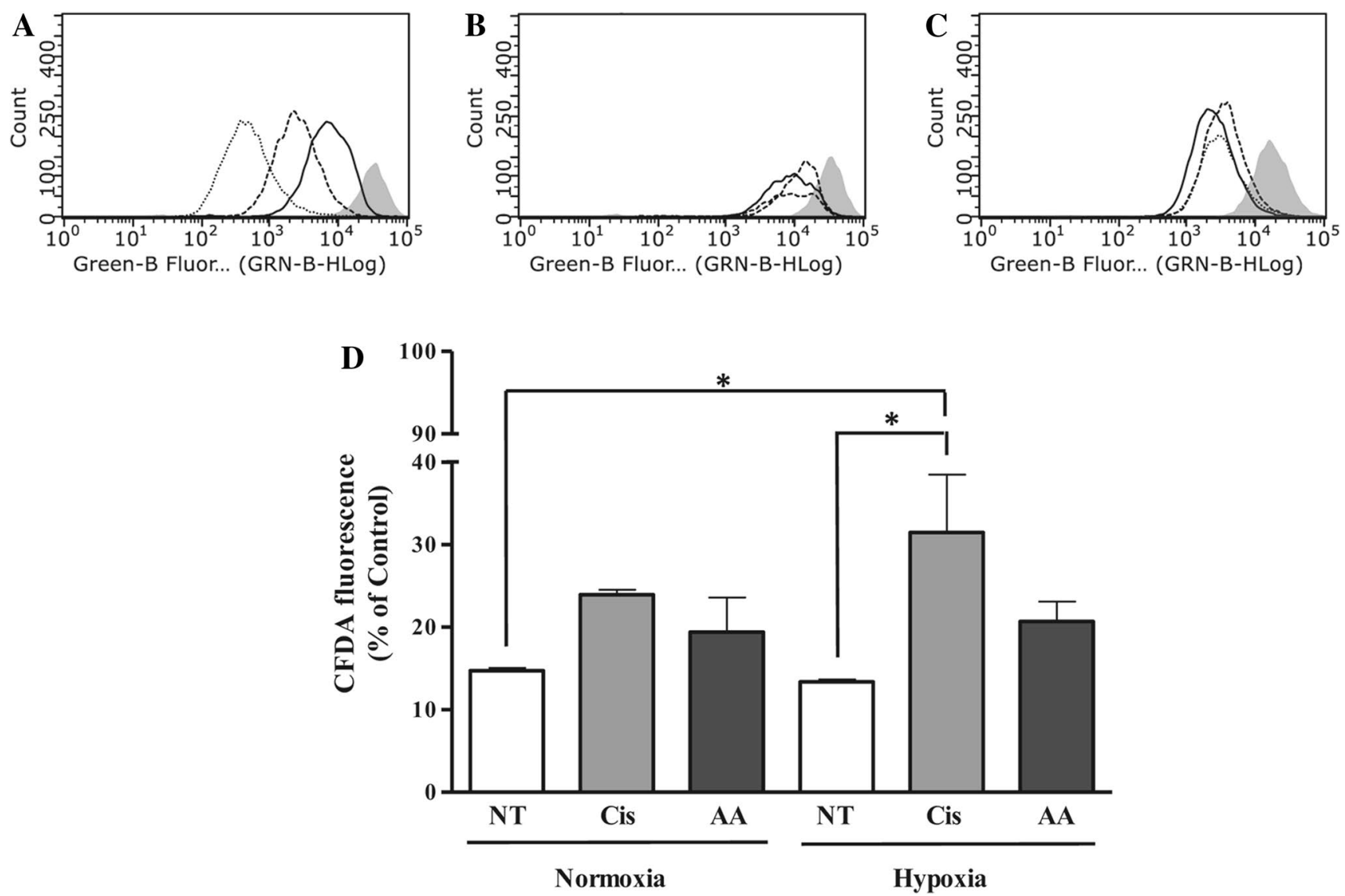

Fig. 2 Effect of cisplatin and AA treatment on cell proliferation in U87-MG cells. Representative flow cytometric plots showing CFDA-SE fluorescence intensity in non-treated controls (a) immediately after staining with CFDA (gray fill) and at 24 (straight lines), 48 (dashed lines), and 72 (dotted lines) hours and under normoxia; following $48 \mathrm{~h}$ of incubation for control (straight lines), cisplatin (dashed lines) and AA (dotted lines) treatments with non-treated

\section{Induction of apoptosis in U87-MG cells}

Having shown that cell proliferation and cell cycle are significantly regulated by cisplatin but not by AA treatment, induction of apoptosis was examined over $72 \mathrm{~h}$ following treatment of cells with cisplatin and AA using the $\mathrm{EC}_{50}$ concentration determined by cell viability assays. The total apoptotic population was determined by combining the cell population staining positively for Annexin-V alone (early apoptosis) with that staining positively for both Annexin-V and PI (late apoptosis). The total apoptotic population following $48 \mathrm{~h}$ of drug treatment with AA under hypoxia was significantly greater than the equivalent treatment under normoxia (Fig. 5 d; $207 \pm 131$-fold vs. $3.1 \pm 0.3$-fold respectively; $p<0.001$ ), in addition to both the normoxic (Fig. $5 \mathrm{~d}$ $16.8 \pm 9.6$-fold; $p<0.01$ ) and hypoxic (Fig. $5 \mathrm{~d} 0.8 \pm 0.1$ fold; $p<0.001)$ populations following $48 \mathrm{~h}$ of cisplatin treatment. control immediately after incubation with CFDA (gray fill) under normoxia (b) and hypoxia (c). Graphical representation of cell proliferation as determined by mean CFDA-SE fluorescence intensity (d) following $48 \mathrm{~h}$ of treatment under normoxia and hypoxia. NT nontreated, Cis Cisplatin, AA Asiatic acid. Data represent mean \pm SEM of three independent experiments. Statistical significance determined by One-Way ANOVA with Dunnett's post hoc test $(p<0.05)$

Early-phase apoptosis significantly increased following $72 \mathrm{~h}$ of AA treatment under normoxia in U87-MG cells when compared to non-treated controls (Fig. 5 e $3.0 \pm 0.8$-fold; $p<0.01$ ), a level of apoptosis that was significantly greater than the equivalent population in SVGp12 cells (Fig. 5 e $1.0 \pm 0.1$-fold; $p<0.01$ ). AA treatment also induced a significant increase in late-phase apoptosis compared to non-treated control following $24 \mathrm{~h}$ of treatment under normoxia (Fig. 5e $5.9 \pm 1.0$-fold; $p<0.001)$. Interestingly, the proportion of late-phase apoptosis induced by AA treatment at both 48 h (Fig. 5 e $4.4 \pm 0.3$-fold; $p<0.01$ ) and 72 h (Fig. 5 e $3.3 \pm 0.2$-fold; $p<0.001)$ under hypoxia was significantly greater than the equivalent treatment under normoxia (Fig. 5 e 48 h, $2.3 \pm 0.3$-fold; 72 h, $0.4 \pm 0.1$-fold). 

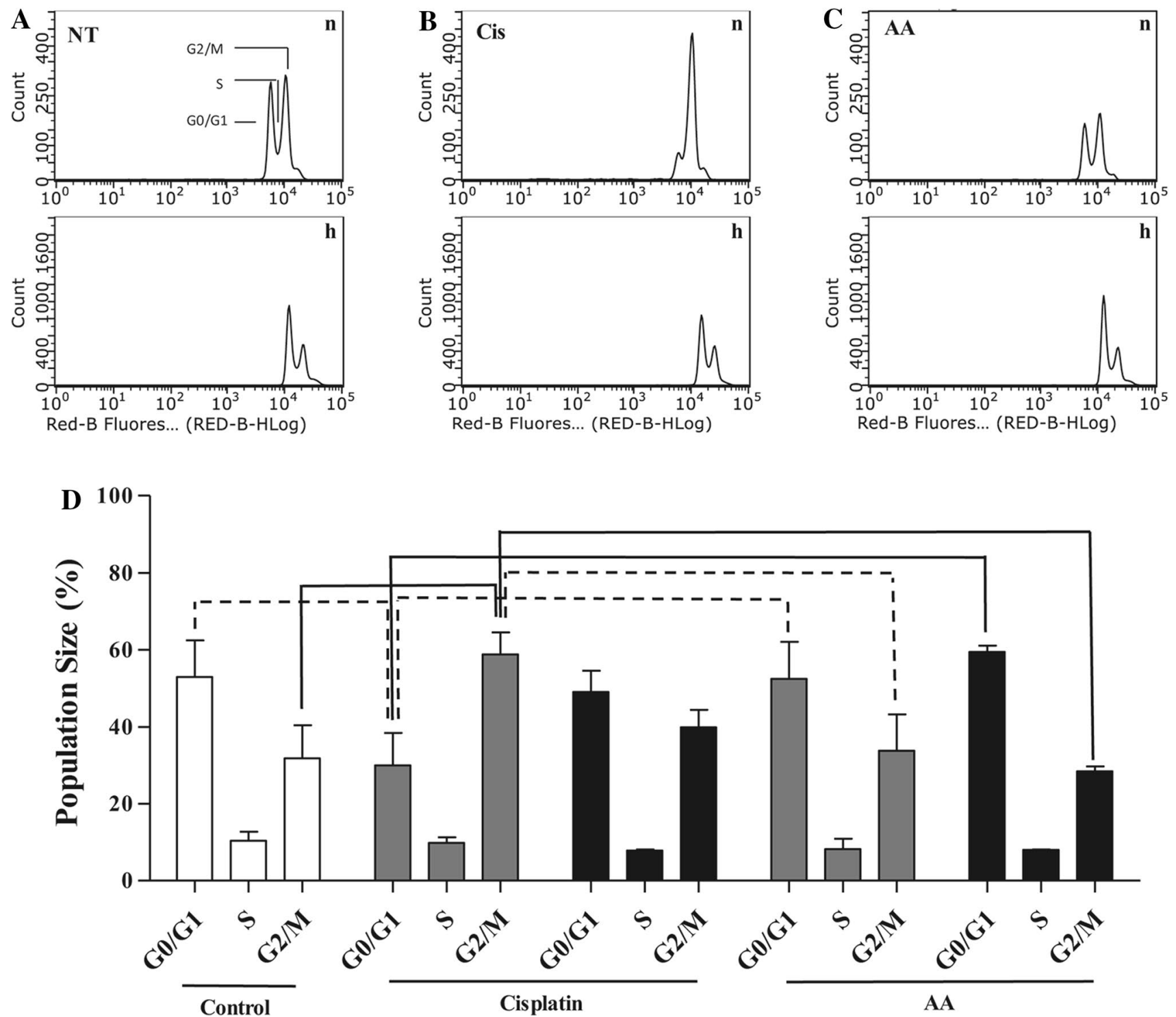

Fig. 3 Effect of cisplatin and AA treatment on cell cycle in U87-MG cells. Representative flow cytometric plots showing PI fluorescence intensity following $48 \mathrm{~h}$ incubation for (a) non-treated, (b) cisplatin, and (c) AA treatments under normoxia (n) and hypoxia (h). (d) Cell cycle analysis of U87-MG cells following $48 \mathrm{~h}$ of cisplatin treatment

\section{Wound healing/migration assay in U87-MG cells}

Finally, cell migration was examined using the wound healing assay to determine any effect of cisplatin or AA under normoxia and hypoxia. Under normoxia in nontreated cells, the scratch completely closed during the 18-h incubation (Fig. 6a, b). Treatment with cisplatin produced a small but significant reduction in wound healing compared to control (Fig. 6b, 97.0 $\pm 1.0 \% ; p<0.001$ ), with AA producing a larger reduction in cell migration under the same condition compared to control (Fig. 6b, and AA treatment (white: control, gray: normoxia, black: hypoxia). Data represent mean \pm SEM of three independent experiments. Statistical significance determined by ANOVA with Bonferroni's post hoc test ( $p<0.05$, dotted line; $p<0.01$, solid line comparisons)

$36.9 \pm 0.7 \% ; p<0.001)$. Importantly, the reduction in migration produced by AA was significantly greater than the reduction produced by cisplatin treatment under normoxia $(p<0.001)$. Hypoxia itself significantly reduced wound healing in control cells when compared to normoxia (Fig. 6 b, $26.9 \pm 1.9 \%$ vs. $100 \%$ respectively; $p<0.001)$. Under hypoxia, neither drug treatment with cisplatin $(33.3 \pm 3.5 \%)$, nor AA $(36.4 \pm 3.7 \%)$ significantly changed cell migration when compared to hypoxic control. 
A NT Cis AA NT Cis AA NT Cis AA Cyclin B1
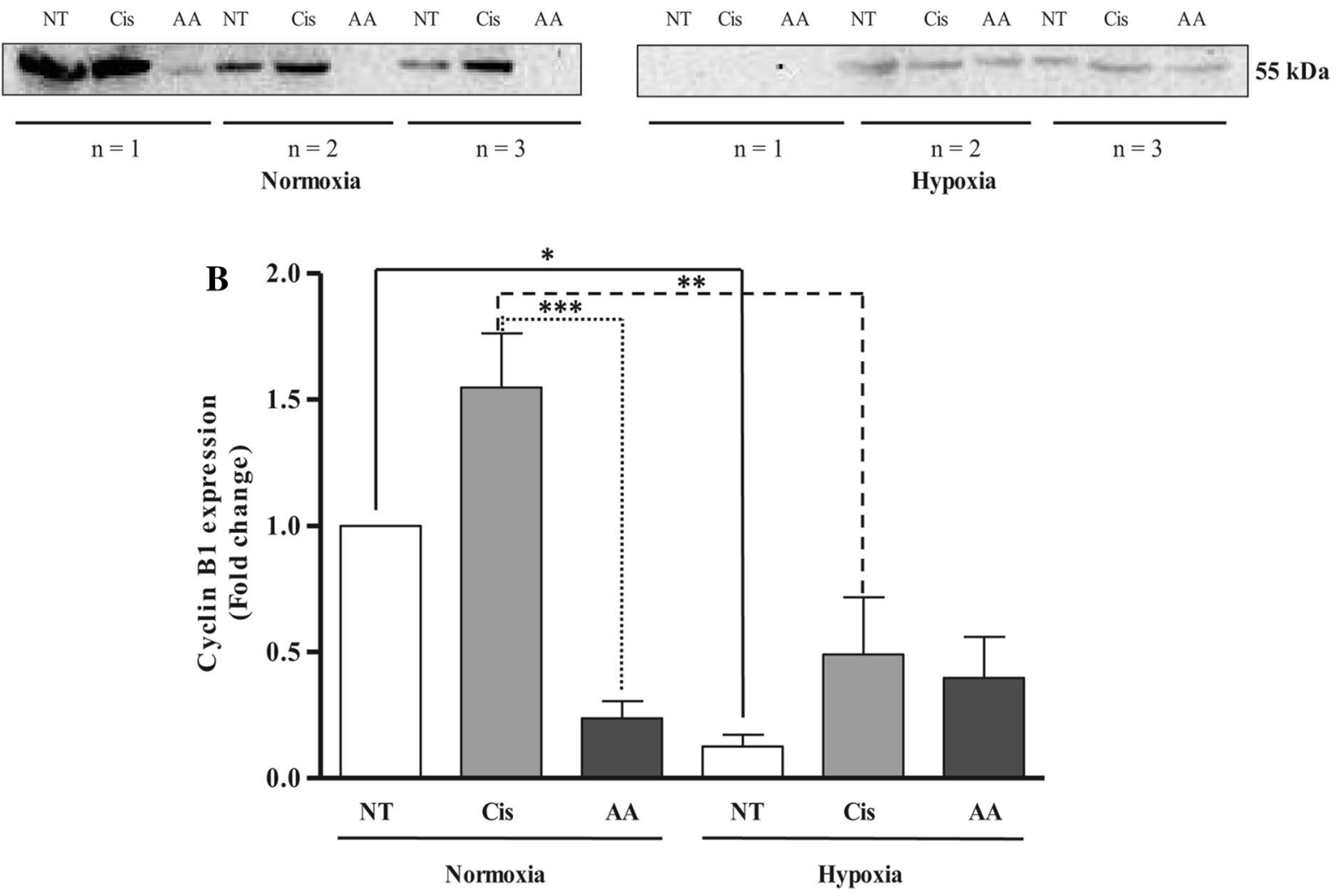

Fig. 4 Western blot analysis for cyclin B1 expression in cisplatinand AA-treated U87-MG cells under normoxia and hypoxia (a); graphical representation of fold change in cyclin B1 expression compared to non-treated normoxia control (b). NT non-treated, Cis cispl- atin, AA Asiatic acid. Data represent mean \pm SEM of three independent experiments. Statistical significance determined by ANOVA with Bonferroni's post hoc test $(p<0.05)$

Both cisplatin and AA produced a decrease in U87-MG cell viability in a time- and concentration-dependent manner. As cisplatin exerts its cytotoxicity by forming DNA lesions, this mechanism of action delayed reductions in cell viability until after $48 \mathrm{~h}$ of treatment $[6,29]$. AA demonstrated greater cytotoxicity in the U87-MG cell line than in SVGp12, a finding that correlates with a recent study which also observed consistently lower cell viability in U87-MG cells compared to SVGp12 cells [30]. It has been suggested that reduced cell viability following AA treatment is due to endoplasmic reticulum stress as a result of activated GRP78 and an increase in intracellular calcium level, which decreases the mitochondrial membrane potential, leading to cell death $[17,18]$.

Due to DNA intercalation, cisplatin is known to disrupt the cell cycle [31, 32], an effect replicated in this study where a reduction in the rate of proliferation of U87-MG cells and cell cycle arrest in the G2/M phase was observed under normoxia. Cyclin B1 and cyclin-dependent kinase 1 (CDK1) specifically regulate cell's entry into mitosis, and an increase in cyclin B1 expression observed by western blotting confirmed cell cycle arrest in the G2/M phase of 

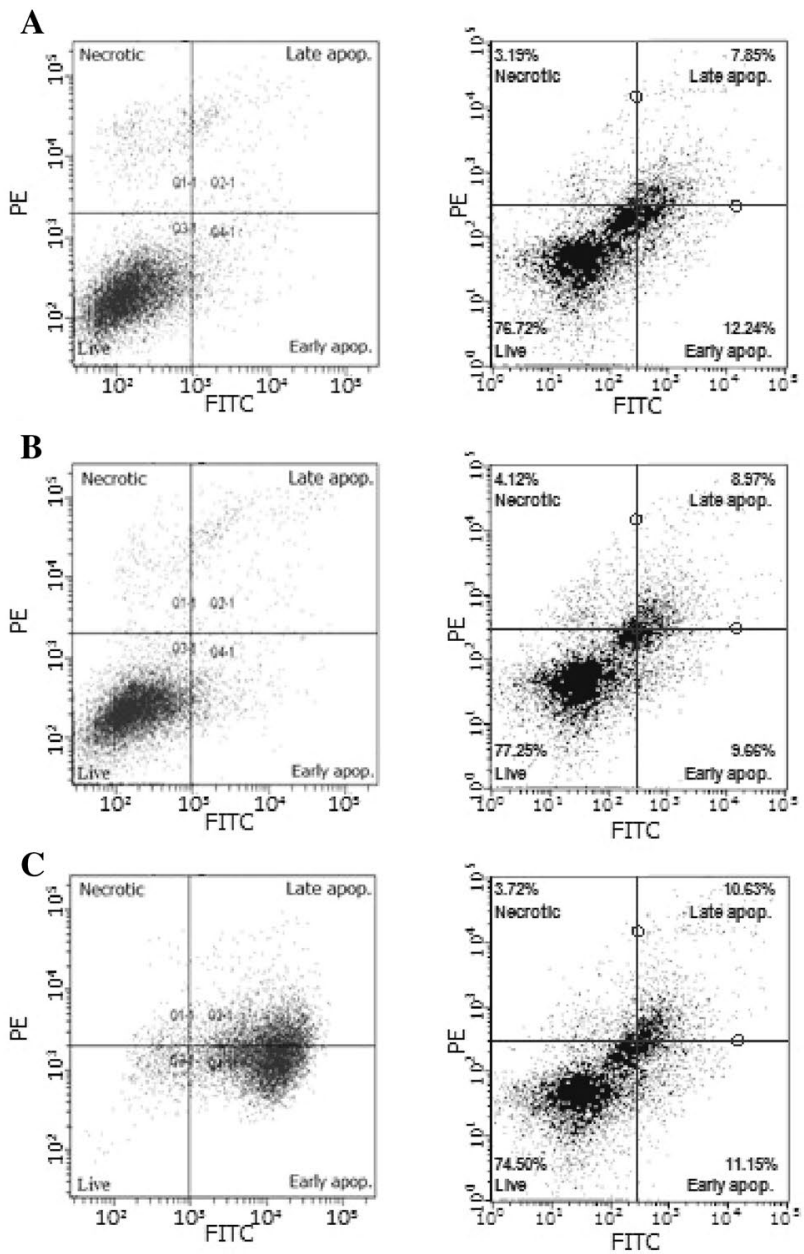

Fig. 5 Induction of apoptosis following 48-h treatment of the U87-MG cell line under normoxia (n) and hypoxia (h) with cisplatin or AA. Representative dot plots showing fluorescence intensity of PI vs Annexin-V staining in (a) non-treated, (b) cisplatin, (c) AA. Relative proportion of total apoptotic U87-MG cells following 24, 48, and $72 \mathrm{~h}$ of cisplatin and AA treatment under normoxia and hypoxia (d),

cisplatin-treated cells under normoxia [33]. Although AA has formerly been reported to induce a $\mathrm{G} 2 / \mathrm{M}$ phase arrest in RPMI 8226 cells [16] and S-G2/M arrest in MCF-7 and MDA-MB-231 breast cancer cell lines [34], in U87-MG cells under normoxia or hypoxia, AA did not show any significant changes in cell proliferation or cell cycle distribution. This is in agreement with previous studies that used glioblastoma cell lines and found that AA inhibits cell viability mainly via cell death, but their effects on cell proliferation or cell cycle have not been reported [30].

Decrease in oxygen supply to cells leads to biochemical changes that either result in cell death or adaptation to hypoxia regulated by HIF-1 $\alpha$ [35]. This effect is reportedly due to the cyclin-dependent kinase inhibitor p $27^{\text {Kip1 }}$ that inhibits the activation of cyclin E-Cdk2 or cyclin
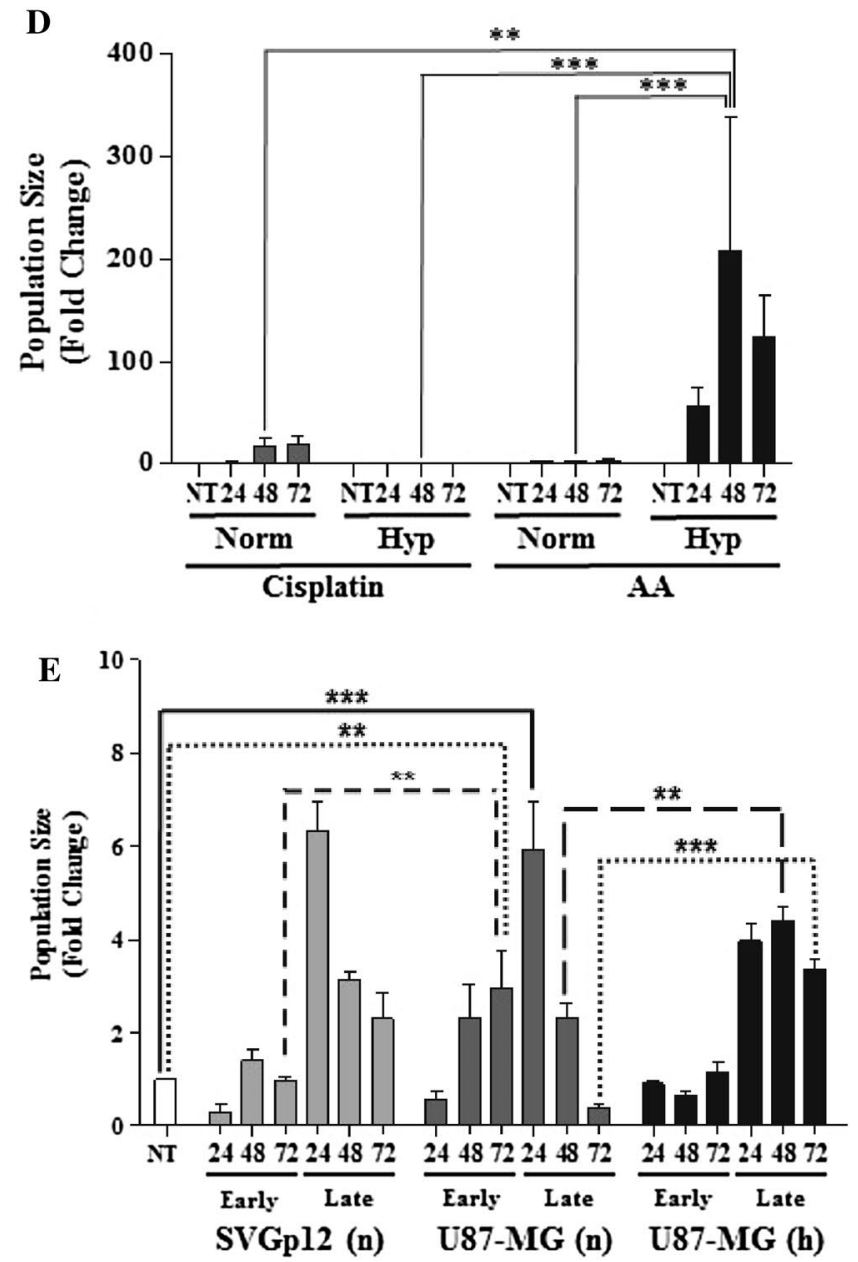

data normalized to normoxic non-treated cells. Relative proportions of early and late apoptotic cells following 24,48 , and $72 \mathrm{~h}$ of AA treatment (e) under normoxia and hypoxia, data normalized to nontreated SVGp12 cells. Data represent mean \pm SEM of three independent experiments. Statistical significance determined by ANOVA with Bonferroni's post hoc test $(p<0.05)$

D-Cdk4 complexes thus controlling cell cycle progression at G1 phase [36]. Hypoxia results in a slower cell cycle progression, whereas moderate hypoxia (e.g., 1\%) induces pre-DNA-synthetic (pre-S-phase) arrest in cells, while cells in the other phases of cell cycle, progress to late G1 phase before they arrest [37]. This transient arrest in G1 phase has been described as a possible mechanism to protect cells from proceeding into the $\mathrm{S}$ phase, where they are more sensitive to hypoxia-related DNA injuries [38]. Cisplatin treatment of U87-MG cells under hypoxia decreased cell proliferation; however, the number of cells arrested in G2/M phase of cell cycle following hypoxic cisplatin treatment was lower than under normoxia. AA treatment under hypoxia did not produce significant changes in cell proliferation or cell cycle; however, a greater population of cells 

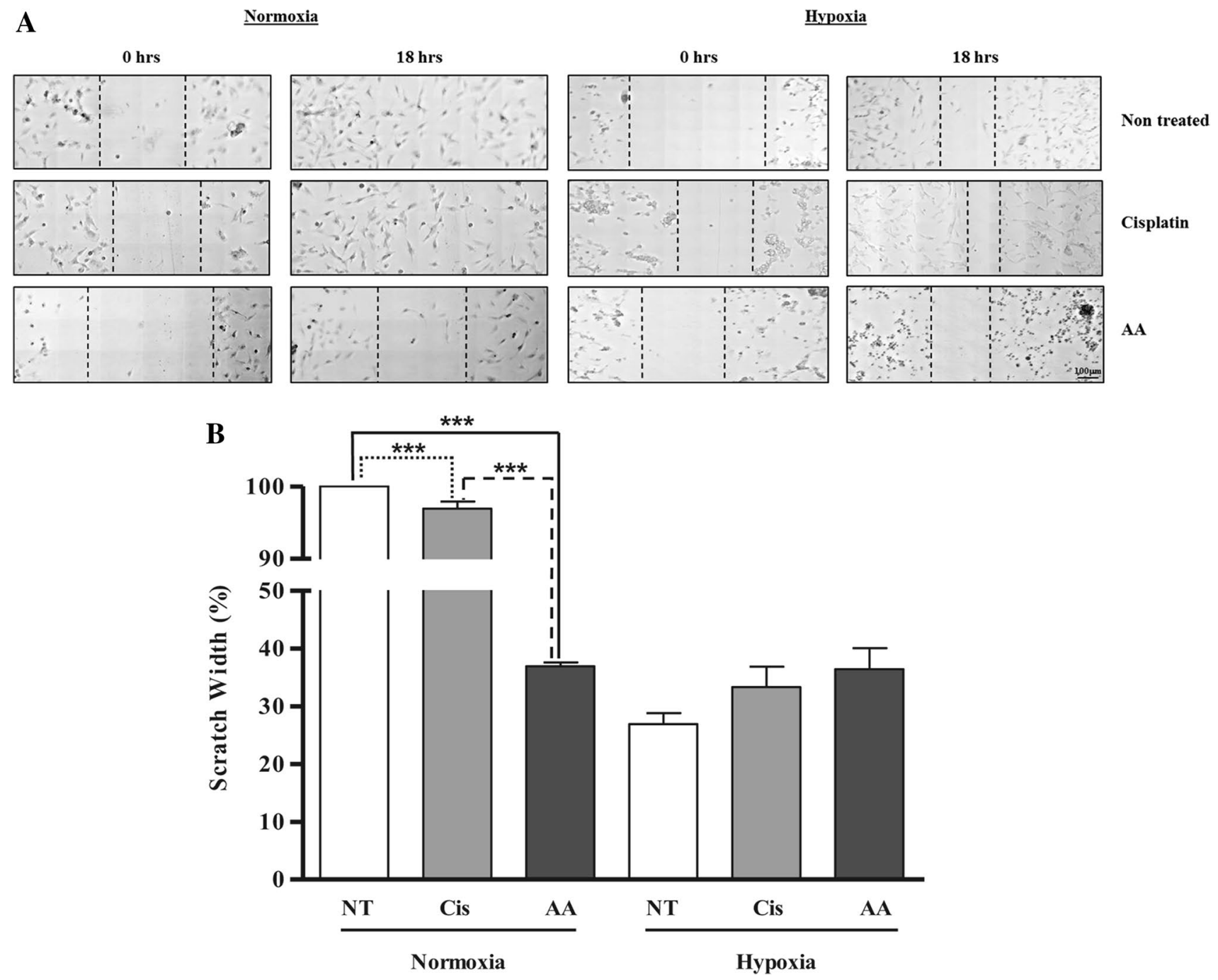

Fig. 6 Inhibition of wound healing/migration by cisplatin and AA treatment in U87-MG cells under normoxia and hypoxia. (a) Representative microscopy images showing initial scratch and subsequent width following $18 \mathrm{~h}$ of incubation. (b) Graphical representation of wound healing following $18 \mathrm{~h}$ of treatment under normoxia

and hypoxia with results expressed as a percentage of initial wound width. NT non-treated, Cis cisplatin, AA Asiatic acid. Data represent mean \pm SEM of three independent experiments. Statistical significance determined by One-Way ANOVA with Bonferroni's post hoc test $(p<0.05)$

was observed in the G0/G1 phase of cell cycle. The lower levels of cyclin B1 expression under hypoxia in comparison to normoxia along with an increase in cell populations at G0/G1 phase confirms that cells were not arrested in G2/M phase of cell cycle.

Under normoxia, a time-dependent increase in apoptosis was observed in U87-MG cells following cisplatin treatment; a finding in agreement with previous studies conducted using cisplatin [30, 39]. Cisplatin exerts an additive cytotoxic effect on cells as they proliferate and a prolonged exposure to cisplatin leads to apoptotic cell death [31]. Cell proliferation is an important factor for the cytotoxic effects of cisplatin due to its mechanism of action. As hypoxia results in slower cell proliferation, the total apoptotic population of cells following hypoxic cisplatin treatment was lower than normoxic. This finding has been confirmed in other studies where a reduced efficacy of cisplatin under hypoxia was observed [24, 40].

Early and late apoptotic cells are distinguished by a loss of membrane integrity and propidium iodide staining in late apoptotic cells [41]. A large proportion of SVGp12 and U87-MG cells were observed in late apoptosis, confirmed by Annexin-V and PI binding, following AA treatment under both normoxia and hypoxia. Interestingly, a timedependent shift in the proportion of cells in late apoptosis back into the early apoptotic quadrant was observed for normoxic SVGp12 and U87-MG cells following AA treatment, possibly suggesting a loss of efficacy of AA treatment 
over time following a single-drug treatment. This is not a surprising result as AA has been shown in vivo to generate a large number of phase I metabolites, and additionally a number of cytochrome p450 enzymes such as CYP2C9 are known to be highly expressed in brain tumors [42, 43]. This effect was not observed following hypoxic AA treatment and a large number of late apoptotic cells were observed which did not change significantly over $72 \mathrm{~h}$. AA causes DNA fragmentation and also induces a loss of phosphatidylserine symmetry that results in phosphatidylserine being exposed on the outer cell membrane [17, 34]. AA-mediated cell death in U87-MG cells involves caspase-9 and caspase- 3 activation and intracellular calcium release that triggers a biochemical cascade resulting in calpain activation and subsequent cell death due to breakdown of the cellular architecture [17, 34, 44]. As AA cytotoxicity is not dependent on cell proliferation, an overall increase in apoptotic population of AA-treated cells was observed under hypoxia in comparison to cisplatin.

The in vitro scratch assay is a method of studying cell migration. GBMs are characterized by an aggressively invasive phenotype that leads to infiltration into the surrounding brain tissue, a characteristic which makes it difficult to eliminate with gross resection and chemotherapy, thus any treatment resulting in a decrease of the invasive phenotype may have therapeutic potential. When a cell monolayer is wounded or scratched, it responds to the cell-cell disruption by increasing growth factors at the wound site and ultimately results in healing of the wound through migration and cell proliferation [45]. Microscopic analysis following normoxic and hypoxic AA treatment showed rounded cells, a characteristic of apoptotic cell death [46]. A larger proportion of apoptotic cells were observed under hypoxia than under normoxia, suggesting again that AA does not regulate cell proliferation or cell cycle but instead exerts its cytotoxicity via inducing cell death. As cells proliferate slowly under hypoxia and cells may undergo cell cycle arrest or senescence, an overall reduction in wound healing was also observed vs normoxic control [47]. As cisplatin mainly exerts its cytotoxicity after $48 \mathrm{~h}$ of incubation, the lack of efficacy of cisplatin on wound healing under normoxia may be explained in part by the shorter time scale used for these experiments.

Results of this study collectively demonstrate the cytotoxic potential of AA on in vitro glioblastoma cells. Although AA did not regulate cell proliferation and cell cycle progression of SVGp12 and U87-MG cells, a higher proportion of cells underwent apoptosis under hypoxia. In contrast to cisplatin treatments under hypoxia, a greater efficacy of AA on induction of cellular apoptosis and a significant delay in wound healing were observed. With its reduced side effect profile and increased time course for cytotoxicity under both normoxia and hypoxia, these data suggest that AA has the potential to become an alternative therapy for the treatment of glioma.

Acknowledgements The authors would like to thank the School of Pharmacy and Biomedical Sciences at the University of Central Lancashire for providing financial support.

Funding This study was self-funded by FK Thakor and the School of Pharmacy and Biomedical Sciences at the University of Central Lancashire.

\section{Compliance with ethical standards}

Conflict of interest The authors declare that they have no conflict of interest.

Ethical approval This article does not contain any studies with human participants or animals performed by any of the authors.

Open Access This article is distributed under the terms of the Creative Commons Attribution 4.0 International License (http:// creativecommons.org/licenses/by/4.0/), which permits unrestricted use, distribution, and reproduction in any medium, provided you give appropriate credit to the original author(s) and the source, provide a link to the Creative Commons license, and indicate if changes were made.

\section{References}

1. Cahill KE, Morshed RA, Yamini B (2016) Nuclear factor-kap$\mathrm{paB}$ in glioblastoma: insights into regulators and targeted therapy. Neuro Oncol 18:329-339. doi:10.1093/neuonc/nov265

2. Preusser M, de Ribaupierre S, Wohrer A, Erridge SC, Hegi M, Weller M, Stupp R (2011) Current concepts and management of glioblastoma. Ann Neurol 70:9-21. doi:10.1002/ana.22425

3. Bobustuc GC, Baker CH, Limaye A, Jenkins WD, Pearl G, Avgeropoulos NG, Konduri SD (2010) Levetiracetam enhances p53-mediated MGMT inhibition and sensitizes glioblastoma cells to temozolomide. Neuro Oncol 12:917-927. doi:10.1093/ neuonc/noq044

4. Weller M, Cloughesy T, Perry JR, Wick W (2013) Standards of care for treatment of recurrent glioblastoma-are we there yet? Neuro Oncol 15:4-27. doi:10.1093/neuonc/nos273

5. Zhang J, Stevens MF, Bradshaw TD (2012) Temozolomide: mechanisms of action, repair and resistance. Curr Mol Pharmacol 5:102-114

6. Florea AM, Busselberg D (2011) Cisplatin as an anti-tumor drug: cellular mechanisms of activity, drug resistance and induced side effects. Cancers 3:1351-1371. doi:10.3390/cancers3011351

7. Frezza M, Hindo S, Chen D, Davenport A, Schmitt S, Tomco D, Dou QP (2010) Novel metals and metal complexes as platforms for cancer therapy. Curr Pharm Des 16:1813-1825

8. Tezcana S, Özdemirb F, Turhalc S, Vehbi İzzettin F (2013) High performance liquid chromatographic determination of free cisplatin in different cancer types. Der Pharma Chemica 5:169-174.

9. Liu L, Simon MC (2004) Regulation of transcription and translation by hypoxia. Cancer Biol Ther 3:492-497

10. Maxwell PH, Pugh CW, Ratcliffe PJ (2001) Activation of the HIF pathway in cancer. Curr Opin Genet Dev 11:293-299

11. Giaccia A, Siim BG, Johnson RS (2003) HIF-1 as a target for drug development. Nat Rev Drug Discov 2:803-811. doi:10.1038/nrd1199 
12. Semenza GL (2000) HIF-1: mediator of physiological and pathophysiological responses to hypoxia. J Appl Physiol (1985) 88:1474-80.

13. Yang L, Lin C, Wang L, Guo H, Wang X (2012) Hypoxia and hypoxia-inducible factors in glioblastoma multiforme progression and therapeutic implications. Exp Cell Res 318:2417-2426. doi:10.1016/j.yexcr.2012.07.017

14. Gohil KJ, Patel JA, Gajjar AK (2010) Pharmacological Review on Centella asiatica: A Potential Herbal Cure-all. Indian. J Pharm Sci 72:546-556. doi:10.4103/0250-474X.78519

15. Lee KY, Bae ON, Serfozo K, Hejabian S, Moussa A, Reeves M, Rumbeiha W, Fitzgerald SD, Stein G, Baek SH, Goudreau J, Kassab M, Majid A (2012) Asiatic acid attenuates infarct volume, mitochondrial dysfunction, and matrix metalloproteinase-9 induction after focal cerebral ischemia. Stroke 43:1632-1638. doi:10.1161/STROKEAHA.111.639427

16. Zhang J, Ai L, Lv T, Jiang X, Liu F (2013) Asiatic acid, a triterpene, inhibits cell proliferation through regulating the expression of focal adhesion kinase in multiple myeloma cells. Oncol Lett 6:1762-1766. doi:10.3892/ol.2013.1597

17. Cho CW, Choi DS, Cardone MH, Kim CW, Sinskey AJ, Rha C (2006) Glioblastoma cell death induced by asiatic acid. Cell Biol Toxicol 22:393-408. doi:10.1007/s10565-006-0104-2

18. Kavitha CV, Jain AK, Agarwal C, Pierce A, Keating A, Huber KM, Serkova NJ, Wempe MF, Agarwal R, Deep G (2015) Asiatic acid induces endoplasmic reticulum stress and apoptotic death in glioblastoma multiforme cells both in vitro and in vivo. Mol Carcinog 54:1417-1429. doi:10.1002/mc.22220

19. Lebwohl D, Canetta R (1998) Clinical development of platinum complexes in cancer therapy: an historical perspective and an update. Eur J Cancer 34:1522-1534. doi:10.1016/ S0959-8049(98)00224-X

20. Baruah H, Rector CL, Monnier SM, Bierbach U (2002) Mechanism of action of non-cisplatin type DNA-targeted platinum anticancer agents: DNA interactions of novel acridinylthioureas and their platinum conjugates. Biochem Pharmacol 64:191-200

21. Lanjwani SN, Zhu R, Khuhawar MY, Ding Z (2006) High performance liquid chromatographic determination of platinum in blood and urine samples of cancer patients after administration of cisplatin drug using solvent extraction and $\mathrm{N}$, N'-bis(salicylidene)-1,2-propanediamine as complexation reagent. J Pharm Biomed Anal 40:833-839. doi:10.1016/j. jpba.2005.07.040

22. Siddik ZH (2003) Cisplatin: mode of cytotoxic action and molecular basis of resistance. Oncogene 22:7265-7279. doi:10.1038/ sj.onc. 1206933

23. Wang D, Lippard SJ (2005) Cellular processing of platinum anticancer drugs. Nat Rev Drug Discov 4:307-320. doi:10.1038/ $\operatorname{nrd} 1691$

24. Song X, Liu X, Chi W, Liu Y, Wei L, Wang X, Yu J (2006) Hypoxia-induced resistance to cisplatin and doxorubicin in non-small cell lung cancer is inhibited by silencing of HIF-1 $\alpha$ gene. Cancer Chemother Pharmacol 58:776-784. doi:10.1007/ s00280-006-0224-7

25. Momekov G, Ferdinandov D, Bakalova A, Zaharieva M, Konstantinov S, Karaivanova M (2006) In vitro toxicological evaluation of a dinuclear platinum(II) complex with acetate ligands. Arch Toxicol 80:555-560. doi:10.1007/s00204-006-0078-0

26. Sheleg SV, Korotkevich EA, Zhavrid EA, Muravskaya GV, Smeyanovich AF, Shanko YG, Yurkshtovich TL, Bychkovsky PB, Belyaev SA (2002) Local chemotherapy with cisplatin-depot for glioblastoma multiforme. J Neurooncol 60:53-59

27. Li JF, Huang RZ, Yao GY, Ye MY, Wang HS, Pan YM, Xiao JT (2014) Synthesis and biological evaluation of novel anilinederived asiatic acid derivatives as potential anticancer agents. Eur J Med Chem 86:175-188. doi:10.1016/j.ejmech.2014.08.003
28. Ramanathan M, Sivakumar S, Anandvijayakumar PR, Saravanababu C, Pandian PR (2007) Neuroprotective evaluation of standardized extract of Centella asciatica in monosodium glutamate treated rats. Indian J Exp Biol 45:425-431

29. Jiang M, Yi X, Hsu S, Wang CY and Dong Z (2004) Role of p53 in cisplatin-induced tubular cell apoptosis: dependence on p53 transcriptional activity. Am J Physiol Renal Physiol 287:F1140-7. doi:10.1152/ajprenal.00262.2004

30. Garanti T, Stasik A, Burrow AJ, Alhnan MA, Wan KW (2016) Anti-glioma activity and the mechanism of cellular uptake of asiatic acid-loaded solid lipid nanoparticles. Int $\mathrm{J}$ Pharm 500:305-315. doi:10.1016/j.ijpharm.2016.01.018

31. Sorenson CM, Barry MA, Eastman A (1990) Analysis of events associated with cell cycle arrest at G2 phase and cell death induced by cisplatin. J Natl Cancer Inst 82:749-755

32. St. Germain C, Niknejad N, Ma L, Garbuio K, Hai T and Dimitroulakos J (2010) Cisplatin induces cytotoxicity through the mitogen-activated protein kinase pathways and activating transcription factor 3. Neoplasia 12:527-538.

33. Wang Z, Fan M, Candas D, Zhang TQ, Qin L, Eldridge A, Wachsmann-Hogiu S, Ahmed KM, Chromy BA, Nantajit D, Duru N, He F, Chen M, Finkel T, Weinstein LS, Li JJ (2014) Cyclin B1/Cdk1 coordinates mitochondrial respiration for cellcycle G2/M progression. Dev Cell 29:217-232. doi:10.1016/j. devcel.2014.03.012

34. Hsu YL, Kuo PL, Lin LT, Lin CC (2005) Asiatic acid, a triterpene, induces apoptosis and cell cycle arrest through activation of extracellular signal-regulated kinase and p38 mitogen-activated protein kinase pathways in human breast cancer cells. J Pharmacol Exp Ther 313:333-344. doi:10.1124/ jpet.104.078808

35. Strese S, Fryknas M, Larsson R, Gullbo J (2013) Effects of hypoxia on human cancer cell line chemosensitivity. BMC Cancer 13:331. doi:10.1186/1471-2407-13-331

36. Wartenberg M, Ling FC, Muschen M, Klein F, Acker H, Gassmann M, Petrat K, Putz V, Hescheler J, Sauer H (2003) Regulation of the multidrug resistance transporter P-glycoprotein in multicellular tumor spheroids by hypoxia-inducible factor (HIF-1) and reactive oxygen species. FASEB J 17:503-505. doi:10.1096/fj.02-0358fje

37. Amellem O, Loffler M, Pettersen EO (1994) Regulation of cell proliferation under extreme and moderate hypoxia: the role of pyrimidine (deoxy)nucleotides. Br J Cancer 70:857-866

38. Graeber TG, Peterson JF, Tsai M, Monica K, Fornace AJ Jr, Giaccia AJ (1994) Hypoxia induces accumulation of $\mathrm{p} 53$ protein, but activation of a G1-phase checkpoint by low-oxygen conditions is independent of p53 status. Mol Cell Biol 14:6264-6277

39. Cummings BS, Schnellmann RG (2002) Cisplatin-induced renal cell apoptosis: caspase 3-dependent and -independent pathways. J Pharmacol Exp Ther 302:8-17

40. Wang J, Biju MP, Wang MH, Haase VH, Dong Z (2006) Cytoprotective effects of hypoxia against cisplatin-induced tubular cell apoptosis: involvement of mitochondrial inhibition and p53 suppression. J Am Soc Nephrol 17:1875-1885. doi:10.1681/ ASN.2005121371

41. Patel VA, Longacre A, Hsiao K, Fan H, Meng F, Mitchell JE, Rauch J, Ucker DS, Levine JS (2006) Apoptotic cells, at all stages of the death process, trigger characteristic signaling events that are divergent from and dominant over those triggered by necrotic cells: Implications for the delayed clearance model of autoimmunity. J Biol Chem 281:4663-4670. doi:10.1074/jbc. M508342200

42. Xia B, Bai L, Li X, Xiong J, Xu P, Xue M (2015) Structural analysis of metabolites of asiatic acid and its analogue madecassic acid in zebrafish using LC/IT-MSn. Molecules 20:3001-3019. doi:10.3390/molecules20023001 
43. Knupfer H, Stanitz D, Preiss R (2006) CYP2C9 polymorphisms in human tumors. Anticancer Res 26:299-305

44. Momeni HR (2011) Role of calpain in apoptosis. Cell J 13:65-72.

45. Liang CC, Park AY, Guan JL (2007) In vitro scratch assay: a convenient and inexpensive method for analysis of cell migration in vitro. Nat Protoc 2:329-333. doi:10.1038/nprot.2007.30
46. Kerr JF, Wyllie AH, Currie AR (1972) Apoptosis: a basic biological phenomenon with wide-ranging implications in tissue kinetics. Br J Cancer 26:239-257

47. Welford SM, Giaccia AJ (2011) Hypoxia and senescence: the impact of oxygenation on tumor suppression. Mol Cancer Res 9:538-544. doi:10.1158/1541-7786.MCR-11-0065 